\title{
O atendimento educacional especializado no Ensino Superior: elementos para uma reflexão à luz das recentes políticas de inclusão de pessoas com deficiência nas Instituições de Ensino Superior brasileiras
}

\author{
Educational attendance specialized in Higher Education: elements for reflection in the light of the \\ recent policies of inclusion of people with disabilities in Brazilian Higher Education Institutions \\ Appel spécialiste de l'éducation dans L'enseignement Superieur: éléments pour refléter la lumière de la \\ récente politique d'intégration des personnes handicapées dans les établissements d'enseignement \\ supérieur du Brésil
}

Maria da Penha Feitosa ${ }^{1}$

Universidade Federal do Piaú

Geraldo do Nascimento Carvalho ${ }^{2}$

Universidade Federal do Piauí

Resumo: O presente texto tem o objetivo de discutir a problemática do atendimento educacional especializado no ensino superior no contexto das recentes políticas de inclusão de pessoas com deficiência nas universidades brasileiras, tendo como base documentos oficiais e trabalhos acadêmicos. Trata-se de um estudo bibliográfico, de caráter exploratório, pautado numa abordagem qualitativa e organizado em três tópicos interligados pela história. Inicia com uma introdução seguida aspectos históricos, posteriormente, uma síntese das principais normatizações voltadas para a inclusão das pessoas com deficiência no ensino superior no Brasil acompanhada de relato de pesquisa sobre o tema, finalizando com algumas considerações.

Palavras-chave: Ensino Superior. Inclusão. Políticas públicas.

Abstract: The present text has the objective of discussing the problem of the educational service specialized in higher education in the context of recent policies of inclusion of people with disabilities in Brazilian universities, based on official documents and evidences of contradictions of practice from research. It is a bibliographical study, exploratory in nature, based on a qualitative historical approach, organized in three topics intertwined by history, beginning with an introduction, then historical aspects, later a synthesis of the main norms aimed at the inclusion of people with deficiency in the higher education in Brazil, later, summary of the research result, finishing with the considerations.

Key words: Higher Education. Inclusion. Public policy.

\footnotetext{
${ }^{1}$ Mestre em Educação; doutoranda em Educação pelo Programa de Pós-Graduação da Universidade Federal de Uberlândia (UFU); professora da Universidade Federal do Piauí (UFPI), da área de História da Educação; membro do Núcleo de Estudos, Projetos e Pesquisas em Gestão da Educação (NUPPEGE) da UFPI. E-mail: penha.feitosa@bol.com.br

2 Mestre em Educação; doutorando em Educação pelo Programa de Pós-Graduação da Universidade Federal de Uberlândia (UFU); professor da Universidade Federal do Piauí (UFPI), da área de Sociologia da Educação; membro do Núcleo de Estudos, Projetos e Pesquisas em Gestão da Educação (NUPPEGE) da UFPI. E-mail: profgeraldocarvalho@hotmail.com.br
} 
Résumé : Cet article vise à discuter de la question des services éducatifs spécialisés dans l'enseignement supérieur dans le cadre de l'inclusion récente des personnes handicapées dans les politiques brésiliennes des universités, sur la base des documents officiels et des preuves de contradictions pratiques de la recherche. Ceci est une étude bibliographique, d'exploration, basée sur une approche qualitative historique, nous présentons organisé en trois thèmes liés par l'histoire, en commençant par une introduction, puis historique, puis un résumé des principales normes ciblées pour l'inclusion des personnes handicapés dans l'enseignement supérieur au Brésil résumé plus tard des résultats de la recherche, se terminant par des considérations.

Mots clés: Enseignement Supérieur. Inclusion. Politiques publiques.

\section{Introdução}

A década de 1990 foi um período profícuo em termos de legislação voltada para a educação, especificamente para o movimento reconhecido como educação inclusiva. O sentido proclamado oficialmente era tentar corrigir anos e anos de exclusão garantindo às pessoas com deficiência o direito à educação em Instituições de Educação Superior ${ }^{3}$, primeiramente na educação básica, mais recentemente no ensino superior focando todas as modalidades de ensino. Foi um momento de disputa político-ideológica entre os que por muito tempo tiveram como reverter a situação de exclusão social em que viviam milhares de pessoas com deficiência e nada fizeram e os movimentos sociais voltados para os segmentos marginalizados da sociedade aguçados pela ideia de um país democrático para todos indistintamente. Uma disputa que gerou frutos que reverberaram para as décadas seguintes, principalmente pela ação sem tréguas desses sujeitos sociais.

Com o surgimento do conceito de educação inclusiva, que se tornou um paradigma dada a situação de profunda dependência e necessidades das pessoas com deficiência, a sociedade brasileira passou a vivenciar muitas mudanças não só de concepção sobre a educação dessas pessoas, hoje identificadas como PCD, mas também de políticas públicas e práticas sociais específicas. Isso tem modificado ao longo do tempo a visão de educação que se tinha

\footnotetext{
${ }^{3}$ Por "Instituições de Educação Superior" (IES) entende-se, em consonância com a legislação pertinente e diretrizes políticas do MEC/Inep: universidades, centros universitários, centros federais de educação tecnológica, faculdades integradas, faculdades, faculdades tecnológicas, institutos ou escolas superiores (BRASIL, INEP/MEC, Referenciais de Acessibilidade na Educação Superior e a Avaliação in loco do Sistema Nacional de Avaliação da Educação Superior (SINAES)),2013, p. 3.
} 
anteriormente, que segregava os alunos em instituições especializadas. A tentativa de construir socialmente uma nova postura diante da problemática vem apontando para a direção na perspectiva de uma educação verdadeiramente inclusiva.

Nessa perspectiva é que se tem aprofundado a preocupação com a qualidade das relações sociais e participação das pessoas com deficiência nas demais instituições da vida social, reivindicações históricas dos movimentos sociais, foram aumentando na medida dos movimentos reivindicatórios, por isso estão pautadas nos mais diversos documentos internacionais sobre inclusão, como a Declaração de Salamanca (1994) e a Convenção sobre os Direitos das Pessoas com Deficiência (2006), assinada em Nova York, em 2007, e tem servido para fundamentar as reivindicações pela aplicação das leis para melhoria da vida dessas pessoas. Pela morosidade com que são implementadas na prática cotidiana, essas reivindicações continuam atuais e necessárias para que haja o fortalecimento continuado das condições não só de inclusão, mas de acessibilidade garantida e permanência.

Em relação à inclusão nas Instituições de Ensino Superior, foco da presente reflexão, as políticas tiveram algo a mais em um momento em que ainda se lutava pela redemocratização das instituições para todos os brasileiros e brasileiras. No caso das universidades já havia uma luta pela superação de um processo histórico marcado pela elitização e exclusão dos marginalizados socialmente oriundos das classes trabalhadoras, negros, mulheres e, também, das pessoas com deficiência dessas instituições de ensino. Dessa forma é que se vem reiterando a importância da inclusão no ensino superior, seja por meio de órgãos do governo federal, especialmente o Ministério da Educação, seja nos espaços alternativos criados pelos movimentos sociais e no campo da educação tem-se empreendido ações como resultados dos decretos, portarias e leis na elaboração de políticas direcionadas à garantia do acesso e da permanência de alunos e alunas com deficiência nas instituições de ensino superior. No tópico que segue apresentaremos aspectos históricos de todo esse movimento que envolve as políticas públicas para inclusão social das pessoas com deficiência no Brasil.

\section{$1 \mathrm{~A}$ inclusão social como um direito inerente à pessoa humana: antecedentes históricos}

O que conhecemos hoje como direitos humanos diz respeito aos direitos inerentes a todos os seres humanos, independentemente de raça, sexo, nacionalidade, etnia, idioma, religião ou qualquer outra condição. Conhecê-los historicamente é fundamental, não apenas 
para a sua preservação, mas fundamentalmente para compreender o seu alcance e poder avançar na ampliação da pauta desses direitos e no caráter universal dos mesmos.

Quatro documentos sintetizam o que denominamos aqui de antecedentes históricos dos direitos humanos. O primeiro deles, embora controverso, data 539 a. C, e ficou conhecido como o Cilindro de $\mathrm{Ciro}^{4}$, considerado por alguns estudiosos e contestado por outros, como a primeira Declaração dos Direitos Humanos. Os demais documentos são a Declaração de Direitos da Inglaterra, de 1689, a Declaração dos Direitos do Homem e do Cidadão, de 1789 e a Declaração Universal dos Direitos Humanos, de 1948. Revisitar tais documentos nos ajuda a entender o significado das políticas de atendimento a pessoas com deficiência na educação superior na perspectiva da inclusão social nos dias de hoje.

No Cilindro de Ciro contém uma declaração do rei persa, Ciro II, depois de sua conquista da Babilônia, 539 AC. Segundo essa interpretação, o decreto do Rei Ciro II, que estabelecia o direito aos povos exilados na Babilônia de regressarem às suas terras de origens, teria sido expedido no primeiro ano após a conquista da Babilônia.

O relato acerca do Cilindro de Ciro no site do wikpédia diz que essa interpretação está baseada no livro de Esdras, que se refere ao Cilindro de Ciro como "evidencia da política de Ciro de repatriação dos hebreus após o cativeiro da Babilônia”. De acordo com o site da enciclopédia livre, o livro de Esdras menciona a "restauração de santuários religiosos e a repatriação dos povos deportados" e que esta seria a base da interpretação acima. No entanto, de acordo com o próprio site, alguns estudiosos contestam esta interpretação, alegando que o Cilindro de Ciro identifica apenas santuários mesopotâmicos, e não menciona os judeus, Jerusalém ou Judeia. Por último, o site afirma que a interpretação do Cilindro de Ciro como “precursor da carta de direitos humanos", é considerada anacrônica pelo Museu Britânico e outros estudiosos do assunto.

Estudos de Pedro Miguel (2016) apontam o Cilindro de Ciro como a Primeira Carta de Direitos Humanos reconhecida pela ONU. Na exposição deste autor, o Cilindro de Ciro é o anúncio da liberdade dos escravos e autorização para os povos exilados retornarem às suas terras de origem e que isto está presente nos primeiros artigos da Declaração dos Direitos Humanos de 1948, especialmente o Artigo IV, ao dizer que "Ninguém será mantido em escravidão ou servidão" e que a "escravidão e o tráfico de escravos serão proibidos em todas as suas formas". ${ }^{5}$

\footnotetext{
${ }^{4}$ Cilindro de Ciro: http://dhnet.org.br/direitos/anthist/marcos/cilindro/index.htm

${ }_{5}^{5}$ Para mais informações, ver https://pedromiguel.jusbrasil.com.br/artigos/386326597/voce-sabe-o-que-e-ocilindro-de-ciro)
} 
A Declaração de Direitos da Inglaterra, aprovada pelo Parlamento Inglês, ao fim da Revolução Gloriosa, 1688-1689, é considerada um avanço no chamado campo democrático burguês e também na questão dos direitos individuais, com a garantia da propriedade privada. O poder monárquico ficou submetido ao Parlamento, significando o fim do absolutismo. Declara os direitos e a liberdade dos súditos e é considerado a base do sistema constitucional do Reino Unido.

A Declaração dos Direitos do Homem e do Cidadão, de 1789, é o resultado político da revolução francesa e da vitória da burguesia sobre a nobreza. Essa declaração proclama as liberdades e os direitos fundamentais do homem e serviu de base para a Declaração Universal dos Direitos Humanos, promulgada pela Organização das Nações Unidas - ONU. O Artigo Primeiro da declaração de 1789 estabelece que: "Os Homens nascem livres e iguais em direito”.

A Declaração Universal dos Direitos Humanos, de 1948, além de consagrar as políticas de direitos humanos fundamentais estabelecidas nos documentos anteriores, constitui referência importante para as políticas de inclusão aplicadas no período do pós-segunda guerra mundial até os dias de hoje. Em seu Artigo Primeiro, estabelece que “Todos os homens nascem livres e iguais em dignidade e direitos” e, em seguida, afirma: I - Todos Nascimentos Livres e Iguais; II - Não Discrimine; VII - Somos Todos Iguais perante a Lei; VIII - Os Direitos Humanos são Protegidos por Lei. O texto dessa Declaração serve de base para as políticas de inclusão em diferentes áreas da esfera social, cultural, política, econômica e educacional, retomadas com bastante ênfase a partir dos anos de 1990.

Importante notar que em todos esses momentos subsiste um contexto histórico marcado por conflitos armados generalizados entre povos de uma mesma nação (revoluções inglesa, 1688 e francesa, 1789, marcadas pela luta da burguesia contra a nobreza, portanto, a disputa interna do poder entre diferentes frações das classes dominantes) ou entre diferentes nações (o domínio persa no oriente e a Segunda Guerra Mundial, esta última marcada pelo domínio imperialista na sociedade capitalista moderna. As declarações resultantes desses conflitos constituem cartas de intenções dos grupos vencedores dirigidas aos vencidos, em geral, de caráter pretensamente universal.

No que diz respeito à educação, a Conferência Mundial de Educação para Todos, realizada em Jomtien (Tailândia), em março de 1990, é um marco importante das políticas implementadas nesta área a partir do último decênio do século XX. Dessa Conferência resultou a Declaração Mundial de Educação para Todos, que traz um Plano de Ação voltado para as Necessidades Básicas de Aprendizagem. A partir do diagnóstico de que mais de 100 milhões 
de crianças, sendo 60 milhões mulheres, não têm acesso ao ensino primário; que mais de 960 milhões de adultos, sendo dois terços mulheres, são analfabetos; que mais de 100 milhões de crianças não conseguem concluir o ciclo básico, a Declaração Mundial de Educação para Todos estabelece um compromisso com a inclusão, conforme explicitam os artigos a seguir:

4. Um compromisso efetivo para superar as disparidades educacionais deve ser assumido. Os grupos excluídos - os pobres; os meninos e meninas de rua ou trabalhadores; as populações das periferias urbanas e zonas rurais; os nômades e os trabalhadores migrantes; os povos indígenas; as minorias étnicas, raciais e linguísticas; os refugiados; os deslocados pela guerra; e os povos submetidos a um regime de ocupação - não devem sofrer qualquer tipo de discriminação no acesso às oportunidades educacionais.

5. As necessidades básicas de aprendizagem das pessoas portadoras de deficiências requerem atenção especial. É preciso tomar medidas que garantam a igualdade de acesso à educação aos portadores de todo e qualquer tipo de deficiência, como parte integrante do sistema educativo.

Como consequência e desdobramento da Conferência de Jomtien acontece, em 1994, a Conferência Mundial de Educação Especial, de 07 a 10 de junho de 1994 e da qual resulta a conhecida Declaração de Salamanca, que dispõe sobre princípios, políticas e práticas na área das necessidades educativas especiais, nos seguintes termos:

Toda criança possui características, interesses, habilidades e necessidades de aprendizagem que são únicas;

Sistemas educacionais deveriam ser designados e programas educacionais deveriam ser implementados no sentido de se levar em conta a vasta diversidade de tais características e necessidades;

Aqueles com necessidades educacionais especiais devem ter acesso à escola regular, que deveria acomodá-los dentro de uma Pedagogia centrada na criança, capaz de satisfazer a tais necessidades.

A Declaração de Salamanca, no tocante a responsabilidade dos governos, apresenta as seguintes demandas: 1) Atribui aos governos a mais alta prioridade política e financeira ao aprimoramento de seus sistemas educacionais no sentido de se tornarem aptos a incluírem todas as crianças, independentemente de suas diferenças ou dificuldades individuais; 2) Que os governos adotem o princípio de educação inclusiva em forma de lei ou de política, 
matriculando todas as crianças em escolas regulares, a menos que existam fortes razões para agir de outra forma.

Para a Comunidade Internacional, a recomendação é de endosso da perspectiva de escolarização inclusiva e apoio ao desenvolvimento da educação especial como parte integrante de todos os programas educacionais.

Alguns princípios orientam a educação especial: as escolas devem acomodar todas as crianças independentemente de suas condições físicas, intelectuais, sociais, emocionais, linguísticas ou outras. Devem incluir crianças com algum tipo de deficiência e superdotadas, crianças de rua e que trabalham, crianças de origem remota ou de população nômade, crianças pertencentes a minorias linguísticas, étnicas ou culturais, e crianças de outros grupos desavantajados ou marginalizados. Afirma que o princípio fundamental da escola inclusiva é o de que todas as crianças devem aprender juntas, sempre que possível, independentemente de quaisquer dificuldades ou diferenças que elas possam ter.

$\mathrm{Na}$ esfera nacional, a educação integrada e a reabilitação comunitária representam abordagens complementares àqueles com necessidades especiais. Ambas se baseiam nos princípios de inclusão, integração e participação. Atenção especial deve ser prestada às necessidades das crianças e jovens com deficiências múltiplas ou severas.

No que diz respeito à escola diversos fatores devem passar por mudanças adaptativas no sentido de contribuir para a constituição de escolas inclusivas bem-sucedidas, tais como o currículo, os prédios, a organização escolar, a pedagogia, a avaliação, o pessoal, a filosofia da escola e as atividades extracurriculares. Dentre as áreas prioritárias, estão a educação infantil, preparação parra a vida adulta, educação de meninas e educação de adultos e estudos posteriores. A declaração apresenta também ações orientadas para a comunidade, dentre as quais, parceria com os pais, envolvimento da comunidade, o papel das organizações voluntárias e a conscientização pública.

Finalmente, importante destacar algumas repercussões das deliberações internacionais na legislação brasileira. A Lei de Diretrizes e Bases da Educação Nacional - LDB N ${ }^{\circ}$ 9.394/ 1996, incorpora, no capítulo V, as orientações relativas à Educação Especial, conforme estabelecidas nos artigos 58, 59 e 60:

Art. 58. Entende-se por educação especial, para os efeitos desta Lei, a modalidade de educação escolar oferecida preferencialmente na rede regular de ensino, para educandos com deficiência, transtornos globais do desenvolvimento e altas 
habilidades ou superdotação. (Redação dada pela Lei n ${ }^{\circ}$ 12.796, de 2013).

Art. 59. Os sistemas de ensino assegurarão aos educandos com deficiência, transtornos globais do desenvolvimento e altas habilidades ou superdotação: (Redação dada pela Lei $n^{\circ}$ 12.796, de 2013)

Art. 60. Os órgãos normativos dos sistemas de ensino estabelecerão critérios de caracterização das instituições privadas sem fins lucrativos, especializadas e com atuação exclusiva em educação especial, para fins de apoio técnico e financeiro pelo Poder Público.

Desde a Conferência Mundial de Educação para Todos, em 1990, percebe-se uma inflexão no caráter universal da educação, que passa a assumir o viés focalista das demais políticas relacionadas com os direitos universais da pessoa humana. A educação especial ganha relevo, mas a educação em geral perde seu alcance universal e passa a focar os chamados "grupos excluídos (os pobres, os meninos e meninas de rua ou trabalhadores, as populações das periferias urbanas e zonas rurais, os povos indígenas; as minorias étnicas e raciais, etc”. A Declaração Universal dos Direitos Humanos (1948) afirma que "toda pessoa tem direito à educação", no entanto, a Declaração Mundial sobre Educação para Todos (1990) foca nos grupos acima mencionados, em vez de reafirmar "toda pessoa" como inscrito na DUDH.

\section{PESSOAS COM DEFICIÊNCIA NO ENSINO SUPERIOR: POLÍTICAS PÚBLICAS PARA INCLUSÃO COM ACESSIBILIDADE E PERMANÊNCIA ${ }^{6}$}

De acordo com o IBGE (2010), no Brasil, 45 milhões de pessoas possuem algum tipo de deficiência. Estima-se que 9 milhões destas estão com idade entre 15 e 60 anos. Somente $18,4 \%$ desse grupo geral têm acesso a algum serviço de reabilitação e outros serviços sociais. Os percentuais mais elevados de deficiência são encontrados entre pessoas sem instrução e entre pessoas com o ensino fundamental incompleto, enquanto a quantidade de matrículas de pessoas com deficiência na educação superior pública e privada aumentou 933,6\% entre 2000 e 2010. 6.884 essas pessoas são da rede pública e 13.403 da rede particular, resultado do investimento que os últimos governos têm feito no setor privado. Os Referenciais de Acessibilidade na Educação Superior e a Avaliação in loco do Sistema Nacional de Avaliação da Educação Superior (SINAES) dizem que

\footnotetext{
${ }^{6}$ Para saber mais sobre legislação específica e documentos internacionais, ver http://portal.mec.gov.br/index.php
} 
Na educação superior o debate sobre a inclusão se inscreve na discussão mais ampla do direito de todos à educação e na igualdade de oportunidades de acesso e permanência, com sucesso, nessa etapa de ensino. Paradoxalmente, apesar de um crescente ingresso do alunado que demanda atendimento especial, o que confronta as práticas discriminatórias e a cultura seletiva e elitista da educação superior, dados do Censo da Educação Superior do ano de 2011 demonstram que, em um universo de 6.739.689 estudantes com matrícula, apenas 23.250 apresentam algum tipo de deficiência, o que equivale a um percentual de $0,35 \%$ (INEP, 2012) (BRASIL/INEP, 2013, p. 4).

A atenção à inclusão de pessoas com deficiência no ensino superior brasileiro data de um período relativamente recente, considerando a história de exclusão que marcou a vida desse segmento social no Brasil e as crescentes necessidades em um mundo cada vez mais exigente. O Aviso Curricular n 277, de maio de 1996, foi enviado aos reitores e se constituiu no primeiro documento direcionado ao atendimento educacional especializado no Ensino Superior, como descrito em 8 de maio de 1996,

Magnífico Reitor,

A execução adequada de uma política educacional dirigida aos portadores de necessidades especiais possibilita que venham a alcançar níveis cada vez mais elevados do seu desenvolvimento acadêmico. É importante, por isto, registrar o esforço que as Instituições de Ensino Superior - IES empreendem no sentido de adequar-se, estruturalmente, para criar condições próprias, de forma a possibilitar o acesso desses alunos ao $3^{\circ}$ grau (BRASIL/MEC-GM, 1996, p. 1).

Constam, portanto, no documento orientações aos reitores de instituições para se adequarem ao processo de acesso e inclusão de "pessoas com deficiência” nesse nível de ensino e aponta procedimentos básicos requeridos tanto nos processos seletivos, como na oferta de materiais adaptados. Dentre as diretrizes, o documento identifica a necessidade de profissionais preparados e de adaptações físicas e flexibilidade pedagógica que garantam acesso, permanência e sucesso do "aluno com deficiência" no Ensino Superior.

No mesmo ano da publicação do Aviso Curricular $n^{\circ}$ 277, o governo brasileiro sancionou a LDB nº 9.394/96, Lei de Diretrizes e Bases da Educação Nacional -LDBEN, que teoricamente avança em alguns quesitos, no entanto, deixa sérias lacunas, como, por exemplo, o fato de não revelar de forma clara o modo como deve ocorrer o processo de inclusão de “pessoas com deficiência” no Ensino Superior, além de discorrer muito genericamente sobre a obrigatoriedade dos sistemas de ensino, sem apresentar o lugar da "pessoa com necessidades especiais" nesses contextos. 
Art. 58. Entende-se por educação especial, para efeitos desta Lei, a modalidade de educação escolar, oferecida preferencialmente na rede regular de ensino, para educandos portadores de necessidades especiais.

$\S 1^{\circ}$ Haverá, quando necessário, serviços de apoio, especializado, na escola regular, para atender às peculiaridades da clientela da educação especial.

$\S 2^{\circ} \mathrm{O}$ atendimento educacional será feito em classes, escolas ou serviços especializados, sempre que, em função das condições específicas dos alunos, não for possível a sua integração nas classes comuns de ensino regular.

$\$ 3^{\circ}$ A oferta de educação especial, dever constitucional do Estado, tem início na faixa etária de zero a seis anos, durante a educação infantil. (BRASIL/MEC. CAP.V, 1996).

Somente em 1999, o governo assina a Portaria n. ${ }^{\circ} 1.679$, que instituiu condições básicas de acesso e permanência na educação superior ao incluir requisitos de acessibilidade nos instrumentos de avaliação dos cursos de nível superior, listados no mesmo documento. Dentre esses requisitos constam

A utilização de textos ampliados, profissionais preparados, adaptações de espaço físico e flexibilidade pedagógica que garantam acesso, permanência e sucesso do aluno com deficiência, recursos ópticos especiais para as pessoas com visão subnormal/ reduzida; utilização de recursos e equipamentos específicos para cegos: provas orais e/ou em Braille, sorobã, máquina de datilografia comum ou Perkins/Braille, DOS VOX adaptado ao computador; colocação de intérprete no caso de Língua de Sinais no processo de avaliação dos candidatos surdos; utilização de provas orais ou uso de computadores e outros equipamentos pelo portador de deficiência física com comprometimento dos membros superiores; ampliação do tempo determinado para a execução das provas de acordo com o grau de comprometimento do candidato (BRASIL/MEC, 1999)

Mas é a partir da Resolução CNE/CP No 1, de 18 de fevereiro de 2002, que cria as Diretrizes Curriculares Nacionais para a Formação de Professores da Educação Básica, que as instituições de ensino superior no Brasil passam a prever em sua organização curricular a formação docente voltada para atenção à diversidade, contemplando conhecimentos sobre as especificidades dos alunos com necessidades educacionais especiais. Na sequência é promulgada a Lei $n^{\circ}$ 10.436/2002, que reconhece a Língua Brasileira de Sinais - LIBRAS, como meio legal de comunicação e expressão, determinando que sejam garantidas formas institucionalizadas de apoiar seu uso e difusão. A inclusão da disciplina de LIBRAS no currículo nos cursos de formação de professores e de fonoaudiologia tem um peso significativo na problemática da inclusão e passa a ser exigida em todas as instituições públicas e privadas.

Assim como o sistema LIBRAS, a grafia Braille também ganha espaço na legislação através da Portaria 2.678/02, que entre outras coisas, aprova diretrizes e normas para o uso, ensino, produção e difusão em todas as modalidades de ensino, compreendendo o projeto da 
grafia Braille para a Língua Portuguesa e a recomendação para o seu uso em todo o território nacional. Todas essas medidas passam a fazer parte do Programa Educação Inclusiva: direito à diversidade (MEC - 2003), que instituiu o direito à diversidade a fim de "apoiar a transformação dos sistemas de ensino em sistemas educacionais inclusivos", incentiva a formação de gestores e educadores voltados para o atendimento educacional especializado em AEE e às garantias de acessibilidade.

No mesmo ano, 2003, a Portaria n 3.284, institui o Referencial de Qualidade para o Ensino Superior (BRASIL/MEC, 2003), que prevê algo mais específico para a inclusão no Ensino Superior, especialmente no item que trata sobre a previsão do atendimento de pessoa com deficiência, o qual diz que “As IES devem dispor de esquemas alternativos para atendimento de estudantes com deficiência” (BRASIL/MEC, 2003). Segundo essa Portaria,

Art. $1^{\circ}$ Determinar que sejam incluídos nos instrumentos destinados a avaliar as condições de oferta de cursos superiores, para fins de autorização e reconhecimento e de credenciamento de instituições de ensino superior, bem como para renovação, conforme as normas em vigor, requisitos de acessibilidade de pessoas portadoras de necessidades especiais.

Art $2^{\circ}$ A Secretaria de Educação Superior, com apoio técnico da Secretaria de Educação Especial, estabelecerá os requisitos de acessibilidade, tomando-se como referência a Norma Brasil 9050, da Associação Brasileira de Normas Técnicas, que trata da Acessibilidade de Pessoas Portadoras de Deficiências a Edificações, Espaço, Mobiliário e Equipamentos Urbanos.

Em 2007, o Ministério da Educação publicou o Referencial de Qualidade da Educação Superior a Distância, que afirma que "Embora seja um documento que não tem força de lei, ele será um referencial norteador para subsidiar atos legais do poder público no que se referem aos processos específicos de regulação, supervisão e avaliação da modalidade citada” (BRASIL, p. 2). Dentre as recomendações o documento aponta que as instituições devem prever como ações para o atendimento ao acadêmico:

$\mathrm{O}$ atendimento de pessoa com deficiência.

[...]Dispor de esquemas alternativos para atendimento de estudantes com deficiência.

[...]Condições de acessibilidade e utilização dos equipamentos por pessoas com deficiências, ou seja, deve-se atentar para um projeto arquitetônico e pedagógico que garanta acesso, ingresso e permanência dessas pessoas, acompanhadas de ajudantes ou animais que eventualmente lhe servem de apoio, em todos os ambientes de uso coletivo (BRASIL, 2007, p.6-28).

Pela garantia da acessibilidade, o documento reforça a afirmação de que a inclusão está além da garantia de matrícula, por apresentar recomendações em relação ao projeto 
arquitetônico e pedagógico, à permanência e apoio aos acadêmicos com necessidades especiais, como expressa,

para a instalação de polos, um dos requisitos diz respeito às condições de acessibilidade e utilização dos equipamentos por pessoas com deficiências, ou seja, deve-se atentar para um projeto arquitetônico e pedagógico que garanta acesso, ingresso e permanência dessas pessoas, acompanhadas de ajudantes ou animais que eventualmente lhe servem de apoio, em todos os ambientes de uso coletivo (BRASIL/MEC, 2007)

Com o ensino superior a distância constrói-se outra possibilidade de inclusão, no entanto, o movimento social sabia que somente os requisitos contidos na lei não constituía garantia de materialidade da ação inclusiva. Para isso, em 2008, o governo federal lança o documento Política Nacional da Educação Especial na Perspectiva da Educação Inclusiva (BRASIL, 2008), que amplia o texto sobre a permanência no Ensino Superior, atentando para a questão da acessibilidade aos materiais didáticos, às novas tecnologias e às atividades que envolvem o ensino, a pesquisa e a extensão, próprias do ensino superior. O documento também manifesta preocupação com a formação do professor responsável pelo AEE e define o público da educação especial como pessoas com deficiência, transtorno global do desenvolvimento e alta habilidades ou superdotação.

Essa política é que passa a partir de então a nortear as ações de educação inclusiva em todos os níveis de ensino e modalidades ao tempo em que amplia o tex to no que se refere ao ensino superior, afirmando que "na educação superior, a educação especial se efetiva por meio de ações que promovam o acesso, a permanência e a participação dos alunos” (BRASIL, 2008a, p.11). Estas ações envolvem o planejamento e a organização de recursos e serviços para a promoção da acessibilidade arquitetônica, nas comunicações, nos sistemas de informação, nos materiais didáticos e pedagógicos, que devem ser disponibilizados nos processos seletivos e no desenvolvimento de todas as atividades que envolvam o ensino, a pesquisa e a extensão.

Ainda sobre o documento Política Nacional da Educação Especial na Perspectiva da Educação Inclusiva, o mesmo visa garantir e fortalecer o AEE como componente integrante das propostas pedagógicas, bem como garantir um sistema educacional inclusivo em todos os níveis através da igualdade de oportunidades. Trata-se do primeiro documento que aponta a estruturação de núcleos de acessibilidade para o ensino superior como apoio técnico para o AEE.

Um aspecto que chama atenção nessa política é o direcionamento que é feito para as instituições de ensino superior federais, enquanto na prática o aumento do número de 
matrículas de alunos público-alvo da educação especial no Ensino Superior ocorre nas instituições privadas e não nas públicas, como atestam os números do censo do ensino superior de 2011. O que se questiona é como se caracteriza então o AEE neste nível de ensino nas IES privadas quando o texto da política faz menção apenas as IES federais?

Em 2011, o Decreto $\mathrm{n}^{0} 7.611$ dispõe sobre a educação especial, o atendimento educacional especializado e dá outras providências. No Art. $1^{\circ}$ está posto o dever do Estado com a educação das pessoas público-alvo da educação especial será efetivado de acordo com as seguintes diretrizes:

Art. $3^{\circ}$ São objetivos do atendimento educacional especializado:

I - prover condições de acesso, participação e aprendizagem no ensino regular e garantir serviços de apoio especializados de acordo com as necessidades individuais dos estudantes;

II - garantir a transversalidade das ações da educação especial no ensino regular;

III - fomentar o desenvolvimento de recursos didáticos e pedagógicos que eliminem as barreiras no processo de ensino e aprendizagem;

e IV - assegurar condições para a continuidade de estudos nos demais níveis, etapas e modalidades de ensino (BRASIL, 2011b).

Em 2013, o governo federal apresenta aos avaliadores do INEP, dentro da Política Nacional para a Inclusão no Ensino Superior, os Referenciais de Acessibilidade na Educação, que instituem um sistema de Revisão da Legislação sobre avaliação in loco do Sistema Nacional de Avaliação da Educação Superior (BRASIL, 2013). Dentre outras coisas, esse Referencial objetiva servir de subsídio para a ação dos avaliadores acerca de questões pertinentes à inclusão e à acessibilidade em seus diferentes níveis envolvendo estudantes com necessidades de atendimento diferenciado, constituindo-se em mais um passo importante na política de inclusão. Quando a Lei 13.409, de 28 de dezembro de 2016, é promulgada já encontra uma vasta produção de normatizações no campo da educação inclusiva as quais passam a compor o corpo da nova Lei.

A Lei 13.409/16 é considerada uma lei ampla e importante por congregar várias aspirações e projetos na área da inclusão. A partir dela as pessoas com deficiência são incluídas no programa de cotas de instituições federais de educação superior, que já contempla estudantes vindos de escolas públicas, de baixa renda, negros, pardos e indígenas. É por meio desse instrumento legal que, atualmente, as instituições federais de educação superior reservam no mínimo 50\% de suas vagas nos cursos de graduação, por curso e turno, para estudantes que tenham cursado integralmente o ensino médio em escolas públicas. Dentro 
dessa cota, $50 \%$ das vagas deverão ser reservadas a estudantes de famílias com renda igual ou inferior a 1,5 salário mínimo per capita. A nova lei acrescenta as pessoas com deficiência a essa cota, que também será regida pela proporcionalidade em relação à população, medida pelo último censo do Instituto Brasileiro de Geografia e Estatística (IBGE).

Um outro fato importante é que a nova Lei altera a Lei no 12.711, de agosto de 2012, que dispõe sobre a reserva de vagas para pessoas com deficiência nos cursos técnico de nível médio e superior das instituições federais de ensino. Com a alteração o art. 1o da Lei no 12.711 , de 2012 passa a vigorar com o seguinte texto "em cada instituição federal de ensino superior, as vagas de que trata o art. 1@ desta Lei serão preenchidas, por curso e turno, por autodeclarados pretos, pardos e indígenas e por pessoas com deficiência, nos termos da legislação [...]” (BRASIL...). Após apresentação dos principais instrumentos legais até 2016, no tópico seguinte focalizaremos algumas experiências vivenciadas na prática como resultado da implantação das políticas e da legislação criada no movimento da inclusão social de pessoas com deficiência.

\section{Experiências no campo da produção acadêmico-científica}

Para além do estudo especificamente bibliográfico, contamos com experiências que mostram a materialidade do que é posto no nível de leis. Dentre essas experiências, destacamos resultado de pesquisa realizada com professores e professoras da Universidade Estadual de Campinas, em 2008, em trabalho intitulado "Estranhos no ninho: a inclusão de alunos com deficiência na Unicamp”, por Susie de Araújo Campos Alcoba (2008). No seu estudo, Alcoba (2208) destaca as barreiras atitudinais e pedagógicas encontradas pelos docentes. Os professores e professoras entrevistados apontam essas barreiras como o obstáculo mais importante para a inclusão dos alunos com deficiência do propriamente as barreiras físicas. Nas entrevistas realizadas ouviu dos sujeitos depoimentos como "perigoso" ter alunos com cegueira ou mesmo em cadeira de rodas em um curso com laboratório de Química” ou "muito complicado" um aluno anão no curso de Artes Cênicas".

Para a pesquisadora, no estudo, ficaram claras dificuldades por parte dos entrevistados em relação a fazer valer o que está no corpo das leis. Para ela, não lhes ocorre que seja possível mudar o modo como os ambientes e práticas estão organizados para permitir a participação desses alunos. Enquanto um docente opinou que um aluno com limitações físicas "não tem condições de seguir" o curso de formação de ator, porque é "muito baseado no corpo", outro 
disse que o curso para formação de atores trabalha com "artífices que se transformam em personagens, e personagens existem de tudo quanto é tipo". Ou seja, enquanto o primeiro argumentou que aquele aluno terá dificuldade para "arrumar papel", o segundo mostrou acreditar que o ator com alguma limitação, "ao invés de lutar contra a dificuldade, incorpora a dificuldade na criação do personagem".

Outras situações clarificadas com o estudo relacionam-se com o estudante cego diante de um exame radiológico e a questão de atingir ou não os objetivos educativos do curso. Nesse quesito, um docente entrevistado argumentou que "se formos dispensar um aluno, com intenção de ser psiquiatra, de uma atividade ou disciplina difícil de cumprir pela ausência de visão, com a justificativa de que não será essencial para o exercício da especialidade pretendida, teríamos que admitir que outros alunos também deixassem de fazer algumas disciplinas, em função de suas pretensões futuras”.

A única coisa que não se poderia exigir do aluno com cegueira, nesse caso, é o que lhe é impossível fazer, ou seja, encaminhar sozinho um diagnóstico radiológico, o que não seria impossível para outros alunos sem deficiência, assim como não seria impossível para estes fazer qualquer outra atividade. Os sem deficiência poderiam argumentar qualquer outra coisa, menos que é impossível fazer, como acontece com o aluno cego (ALCOBA, 2008), o que deixa claro que o fato de existir uma lei ainda não é garantia de inclusão, pois outras nuances e situações vão surgindo na vida das pessoas com deficiência, que vão demandar muito além de novas normatizações, mas conhecimento, informação e, principalmente, mudança de atitude e disposição dos que lidam com educação no Brasil e de toda a sociedade em relação às políticas de inclusão.

A experiência acima diz respeito a atitudes de professores, que não acreditamos sejam as únicas e sequer a principal dificuldade. Talvez sejam muito minoritárias as posições acima mencionadas, considerando que a qualidade no ensino público mais se deve ao esforço e a dedicação desses profissionais, apesar da crescente degradação das condições de trabalho que historicamente vivenciam

\section{Algumas considerações}

Partindo do exposto, fica uma forte impressão de que há necessidade de mudanças na política de inclusão de pessoas com deficiência no ensino superior, principalmente no que diz respeito à materialidade do objeto. Os documentos tendem a definir acessibilidade apenas em 
relação ao aspecto físico e manuseio de equipamentos e instrumentos, negligenciando os objetivos pedagógicos, assim como a garantia de permanência e ambiência no espaço universitário.

Por outro lado, identifica-se, no conjunto, a presença de grupos de interesse com pensamentos diferenciados e com claros interesses políticos a respeito da inclusão, o que gera políticas também fragmentadas, isoladas do conjunto e de governos, em contraposição com as políticas de Estado, de caráter universal. Na pesquisa realizada na UNICAMP por Alcoba (2008) foram identificadas dificuldades por parte de professores no atendimento das pessoas com algum tipo de deficiência. Número significativo de professores apresenta dúvidas sobre o que e como fazer para romper com tais dificuldades. Assim, para viabilizar um projeto de inclusão e torná-lo verdadeiramente viável e sustentável, ainda requer muito mais que normatizações, requer mudança cultural e de atitude, dos governos, gestores escolares e profissionais da educação em geral. Exige-se levar em consideração a ecologia do ambiente universitário, as necessidades e anseios de todo o sistema escolar, para que este esteja apto a receber esses sujeitos sociais que há muito já deveriam estar socialmente e integralmente fazendo a sua história pelas suas próprias mãos e capacidades.

A inflexão no caráter universal da educação constitui outro dado preocupante, uma vez que provoca o focalismo das políticas relacionadas com os direitos universais da pessoa humana. Enquanto a educação especial isolada ganha relevo, a educação em geral perde seu alcance universal e passa a focar os chamados grupos excluídos, sendo que hoje os excluídos ganharam uma dimensão nunca antes verificada em um contex to de acirramento da exploração capitalista. Nessa seara sérias contradições vão tomando corpo e faz com que a afirmação da Declaração Universal dos Direitos Humanos (1948) “toda pessoa tem direito à educação”, seja suplantada pelo que diz a Declaração Mundial sobre Educação para Todos (1990) ao focar nos excluídos, em vez de reafirmar "toda pessoa” como inscrito na DUDH.

\section{Referências}

ALCOBA, Susie de Araújo Campos. A inclusão de alunos com deficiência na universidade: o desafio pedagógico. Tese de doutorado "Estranhos no ninho: a inclusão de alunos com deficiência na Unicamp”, São Paulo, UNICAMP, 2008.

BALL, S.J.; MAINARDES, J. (Org.). Políticas educacionais: questões e dilemas. São Paulo: Cortez, 2011.

BRASIL/MEC, portal.mec.gov.br > PNLEM > Secretarias > SECAD - Educação Continuada 
BRASIL/MEC. Lei de Diretrizes e Bases da Educação Nacional - LDB 9394/1996: http://portal.mec.gov.br/index.php. Acesso em 29 de agosto de 2018

BRASIL/MEC. Aviso Curricular nº 277, de maio de 1996; Portaria n. ${ }^{\circ}$ 1.679, de 1999; Resolução $\mathrm{CNE} / \mathrm{CP} \mathrm{N}^{\circ}$ 1, de 18 de fevereiro de 2002; Lei ${ }^{\circ}$ 10.436/2002; Portaria 2.678/02; a Portaria $\mathrm{n}^{\mathrm{o}}$ 3.284, de 2003; Decreto $\mathrm{n}^{\mathrm{o}}$ 7.611, de 2011 ; portal.mec.gov.br/. Acesso em 17/05/2018.

BRASIL/MEC/INEP. Referenciais de Acessibilidade na Educação Superior e a Avaliação in loco do Sistema Nacional de Avaliação da Educação Superior (SINAES) parte I - avaliação de cursos de graduação, 2013.

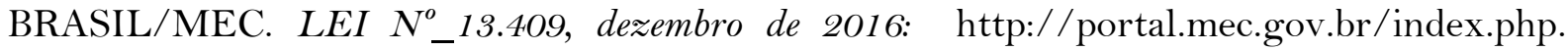
Acesso em 29 de agosto de 2018

ONU. Declaração Universal dos Direitos Humanos, 1948. Organização dos Estados Americanos. Convenção da Guatemala, 2001.

SANTOS, Tatiana; HOSTINS, Regina Célia Linhares. Política Nacional para a Inclusão no Ensino Superior: uma Revisão da Legislação - UNOPAR Cient., Ciênc. Human. Educ., Londrina, v. 16, n.3, p. 194-200, 2015.

UNESCO/WCEFA. Declaração Mundial sobre Educação para Todos. Nova York, março de 1990 (http://www.regra.com.br/educação).

VALDÉS, M. T. M. et al. Inclusão de alunos com NEE no Ensino Superior: O caso da Universidade Estadual do Ceará. In: Congresso Brasileiro de Educação Especial e Encontro da Associação Brasileira de Pesquisadores em 101 Educação Especial, Anais, 11-14 de novembro de 2003, São Carlos: UFSCar, 2003, Fortaleza, 2003. p.271.

https://pt.wikipedia.org/wiki/Declara\%C3\%A7\%C3\%A3o_de_Direitos_de_1689.

Consultado em 02/09/2018

https://pt.wikipedia.org/wiki/Declara\%C3\%A7\%C3\%A3o_dos_Direitos_do_Homem_e_do _Cidad\%C3\%A3o. Consultado em 02/09/2018

http://www.direitoshumanos.usp.br/index.php/Documentos-anteriores-\%C3\%Aocria\%C3\%A7\%C3\%A3o-da-Sociedade-das-Na\%C3\%A7\%C3\%B5es-at\%C3\%A91919/declaracao-de-direitos-do-homem-e-do-cidadao-1 789.html. Consultado em 02/09/2018

https://pedromiiguel.jusbrasil.com.br/artigos/386326597/voce-sabe-o-que-e-o-cilindro-deciro. Consultado em 01/09/2018

http://dhnet.org.br/direitos/anthist/marcos/cilindro/index.htm. Consultado em $01 / 09 / 2018$ 